\title{
Las patronales argentinas ante la lucha obrera y sindical de los años 60
}

\author{
Silvia Simonassi
}

ISHIR-UNR

silviasimonassi@yahoo.com.ar

Title: The Argentine employers facing the workers' and union struggle during the sixties

Resumen: Durante los años 60 y principios de la década siguiente, la lucha obrera y sindical se ubicó en el centro de las preocupaciones de los empresarios argentinos y sus organizaciones. En este artículo analizamos las formas que adoptaron los discursos y las prácticas patronales de Buenos Aires y Rosario, en torno a temas como las dirigencias sindicales, las modalidades de lucha y los procesos de radicalización política, para establecer su relación con los discursos circulantes en torno al "enemigo interno". Para ello, utilizamos un corpus heterogéneo de fuentes escritas y entrevistas orales, del campo obrero y empresario. Palabras clave: Lucha obrera - organizaciones patronales - disciplinamiento - anticomunismo

Abstract: During the 1960s and the beginning of the following decade, the workers and trade-union struggle was at the centre of the concerns of Argentinian businessmen and their organizations. In this article we analyze the forms adopted by the discourses and practices of the employers in Buenos Aires and Rosario, about issues such as union leaderships, the methods of struggle and the processes of political radicalization, to establish their relationship with circulating discourses on the "internal enemy". We use a heterogeneous corpus of written sources and oral interviews, from the workers' and employers' fields. Key words: worker struggle - employers' organizations - disciplining - anticommunism

Recepción: 25 de junio de 2018. Aprobación: 15 de julio de 2018 .

(Archivos, año VII, $\mathrm{n}^{\circ}$ 13, septiembre de 2018, pp. 97-117) 
Durante los años 60 la lucha obrera y sindical se ubicó en el centro de las preocupaciones de los empresarios argentinos y sus organizaciones. En rigor, sería errado afirmar que en algún momento de la historia contemporánea el tema estuvo ausente de sus inquietudes, de sus discursos y de su accionar. Sin embargo, los procesos de radicalización política e ideológica abiertos tras la revolución cubana en el ámbito latinoamericano, la agudización del conflicto de clases y el surgimiento de corrientes antiburocráticas y clasistas durante los 60 en Argentina promovieron cambios en las formas de percibir y actuar ante la lucha obrera en amplios sectores del empresariado argentino.

Recientes investigaciones han profundizado el análisis en la legislación, los discursos y las prácticas de los sectores dominantes argentinos (partidos politicos, Fuerzas Armadas, intelectuales de derecha) durante los 60 y la primera mitad de la década siguiente. Se ha estudiado exhaustivamente la legislación, los debates parlamentarios, los escritos producidos desde diversos grupos e instituciones reflejando la creciente preocupación por el "enemigo interno" y la "guerra revolucionaria" (Mazzei, 1997; Ranalletti, 2011; Franco, 2012a y 2012b; Pontoriero, 2015 y 2018). Sin embargo, menos se ha ahondado en las transformaciones operadas en los discursos y prácticas de las empresas, los empresarios y sus asociaciones.

En la historia argentina del siglo XX, los rasgos que fue adquiriendo el conflicto de clases representó uno de los principales fundamentos de la organización de las patronales (Badaloni y Simonassi, 2008; Simonassi, 2014; Caruso, 2016). En la década del 60 un nuevo impulso asociativo derivó en la conformación de numerosas cámaras de base y asociaciones patronales, para hacer frente a la creciente conflictividad laboral. Durante estos años, la apelación a la intervención del Estado, mediante la modificación de la legislación y la represión de las diversas modalidades que fue adquiriendo el conflicto obrero, fue uno de los rasgos característicos. Paralelamente, las empresas y los empresarios impulsaron en las fábricas relaciones de tipo paternalista, orientadas a apaciguar el conflicto obrero y aislar al activismo.

En este artículo analizamos las formas que adoptaron los discursos y las prácticas patronales de Buenos Aires y Rosario durante los años 60 y el primer tramo de la década siguiente, enfatizando en aquellos de contenido liberal, antisindical y anticomunista. Para ello, utilizamos un corpus heterogéneo de fuentes escritas, en especial la prensa periódica, publicaciones y documentos internos de organizaciones empresarias, sindicales y políticas, así como entrevistas realizadas a empresarios y trabajadores.

En un primer apartado exhibimos algunas cuestiones vinculadas a la mirada empresaria sobre los conflictos y las direcciones sindicales 
en Argentina, para mostrar las transformaciones operadas a principios de la década. En una segunda parte, indagamos en las percepciones y las demandas formuladas por los empresarios ante una modalidad especifica de lucha obrera, hasta entonces la más amenazante según su óptica: las ocupaciones fabriles. En tercer término, mostramos las transformaciones operadas en los discursos y las prácticas patronales al compás de la actuación de vertientes clasistas y de organizaciones armadas en el movimiento obrero. En cuarto lugar, señalamos la importancia de desentrañar la lógica de mecanismos de tipo paternalista, destinados a disciplinar a los trabajadores, procurando frenar los conflictos y aislar el activismo. Finalmente, presentamos un conjunto de conclusiones.

\section{Los dirigentes sindicales y la conflictividad laboral a través de la lente patronal}

Para buena parte de las organizaciones empresarias argentinas, la "Revolución Libertadora" representó un acontecimiento que devolvía las esperanzas de normalizar las relaciones con los trabajadores y los sindicatos, conmovidas durante el peronismo. De hecho, hacia el interior de las plantas se desató una verdadera "revancha" por parte del empresariado, un intento por saldar cuentas con el pasado.

Así, el golpe recondujo los esfuerzos, visibles ya durante el último tramo del peronismo, por incrementar la productividad del trabajo y limitar el poder obrero expresado en las comisiones internas y los cuerpos de delegados. En el plano de las negociaciones salariales y de condiciones de trabajo esperaron reducir el poder sindical, modificar las cláusulas de convenios y limitar las atribuciones de los trabajadores y sus representantes. En el terreno de los conflictos, aspiraron a limitar los derechos, en particular la huelga, y apuntaron a la represión estatal lisa y llana.

De hecho, durante 1956 y 1957 exigieron la intervención del Estado en los numerosos conflictos que estallaron en el sector industrial. Sin embargo, no siempre los resultados se ajustaron a sus expectativas. Así, fueron frecuentes las críticas a las interpretaciones y resoluciones del Tribunal Arbitral que actuaba en los conflictos a partir de 1956 (James, 1981). Las patronales rosarinas, ante una de las diversas huelgas de los trabajadores de frigoríficos, iniciada en el Swift Rosario y extendida a todo el país, mostraron su descontento con la intervención estatal, exigiendo "resolución sumaria" y rechazando los "procedimientos dilatorios y rutinarios de la burocracia". Afirmaban: "con reuniones de fórmula entre funcionarios y partes en litigio no se resuelve nada. Es como si el 
médico esperara salvar la vida del enfermo sentándose pasivamente a la cabecera de su lecho". ${ }^{1}$

Además, fueron frecuentes los pronunciamientos en torno al papel de las direcciones sindicales, a quienes consideraban una minoría en el seno de la clase obrera, que procuraba "imponer soluciones por la violencia", anteponiendo su propia voluntad y por ende actuando "despóticamente". Su conducta configuraba una "verdadera dictadura", un resabio del régimen peronista. Por el contrario, "una gran parte de la masa proletaria [...] reconoce que su parte de contribución positiva [...] consiste en producir más". Para los empresarios, serian los propios asalariados, "sin necesidad de intervención gubernativa, los que habrán de concluir con esta dictadura". ${ }^{2}$ En efecto, durante estos años las críticas se inscribieron en una evaluación del régimen peronista, al que calificaban de tiránico y dictatorial. La supervivencia de rasgos asociados a ese pasado contrariaba la apertura de una nueva etapa, asociada a la "libertad".

Durante el primer año del gobierno de Frondizi las críticas circularon por carriles similares. Mientras se sistematizaban los esfuerzos por aumentar la productividad del trabajo y crecía la conflictividad laboral, las organizaciones empresarias cuestionaron los aumentos salariales dispuestos por el gobierno y levantaron quejas contra las exigencias de reincorporación de despedidos y pago de los días de huelga. La principal publicación de empresarios metalúrgicos de Buenos Aires sostuvo que se introducía "el factor político en cuestiones netamente económicas". Demandaba la superación inmediata de "la actual etapa de desquiciante lucha sindical y que alcancemos una verdadera paz social". ${ }^{3} \mathrm{La}$ Acción Coordinadora de Instituciones Empresarias Libres (ACIEL), por ejemplo, cuestionaba la actuación del Ministerio de Trabajo y de los Departamentos Provinciales, por sus posturas "que habria[n] provocado la admiración del propio Carlos Marx: la que sustenta que las huelgas son, en principio, todas legitimas". ${ }^{4}$

Los empresarios rosarinos, por su parte, cuestionaron también

1. "Conflictos del trabajo y burocracia", en Boletin de Federación Gremial del Comercio y la Industria de Rosario (de aquí en adelante, Boletín), n 501, 2 de marzo de 1957. 2."La única dictadura”, Boletín, n ${ }^{\circ}$ 535, 26 de octubre de 1957.

3. "Acciones del gobierno dirigidas a captar voluntades. Solución política a un problema económico", en Metalurgia, n 196, setiembre 1958.

4. Noticias de ACIEL, 19 de diciembre de 1958, citado en Cúneo, 1984: 222. ACIEL, se conformó a mediados de 1958 con la participación de importantes organizaciones empresarias, como la Unión Industrial Argentina, la Sociedad Rural y la Bolsa de Comercio de Buenos Aires, entre otras. Se caracterizó por representar las voces de los sectores liberales del empresariado. La Federación Gremial del Comercio y la Industria de Rosario participaba de esta nueva entidad y suscribia la totalidad de sus planteos. 
las normas laborales "que anarquizan las relaciones entre patronos y asalariados y establecen el omnímodo predominio de los dirigentes obreros para disponer huelgas, paros y trabajo a desgano". ${ }^{5}$ La nueva ley de asociaciones profesionales, que en lo sustancial recuperaba las premisas de la legislación peronista, era considerada un retorno al pasado, al punto que durante muchos años insistieron en su derogación. ${ }^{6}$

Sin embargo, ya durante el año siguiente, el eje de denuncia se amplió desde una crítica a las dirigencias sindicales heredadas del populismo peronista hacia la identificación del activismo comunista como responsable de la agitación obrera y sindical. Bajo esa óptica -coincidente en responsabilizar a las direcciones sindicales pero divergente en cuanto a la inspiración político ideológica de esas acciones-, se interpretó la conflictividad durante buena parte del desarrollismo frondicista y se desplegaron mecanismos represivos. ${ }^{7}$

En efecto, en correspondencia con el avance de las políticas anticomunistas manifestado en la aplicación del Plan Conintes y en los discursos circulantes en torno al "enemigo interno" como expresión de la conflictividad social y política, los empresarios adjudicaron la conflictividad al accionar de los comunistas. Esa perspectiva se exhibió de manera más nítida en 1961, cuando el proceso de achicamiento de la planta de trabajadores del Estado recayó sobre los ferrocarriles y se sucedieron tres huelgas generales, una de ellas de 72 horas.

Para los empresarios de la ciudad de Rosario, la escalada huelguista consistía en "una exteriorización de "gimnasia revolucionaria" y del poder ejercido por las direcciones gremiales, que obligaban a sus bases a acatarlos "solo por inercia y disciplina dentro de la estructura sindical admitida en una situación legal que coarta la libertad de resistir lo deci-

5."Nota de actualidad", Boletín, n ${ }^{\circ}$ 586, 22 de noviembre de 1958. El gobierno frondicista adoptó como una de sus primeras medidas un incremento masivo de salarios que fue considerado "excesivo" incluso por los sectores industriales volcados al mercado interno.

6. La Prensa, 16 de mayo de 1962, citado en Cúneo, 1984: 242.

7. Tal como aconteció durante la toma del Frigorífico Lisandro de la Torre y la huelga bancaria, donde se aplicaron importantes dosis de represión (Salas, 2006; Acha, 2008). Al año siguiente, en marzo, se aplicó formalmente el Plan Conintes. Mediante este instrumento y ante las "graves perturbaciones" que se sucedian, el gobierno autorizaba a las Fuerzas Armadas a "proceder con toda rapidez y absoluta energía" para restablecer el "orden público", subordinando a las policias provinciales, Decre-

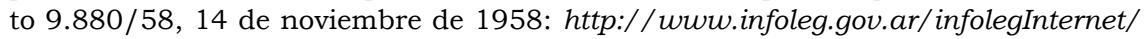
anexos/205000-209999/209052/norma.htm. Al respecto, se ha resaltado que el plan Conintes estuvo destinado a colocar bajo la esfera de las Fuerzas Armadas el combate contra el enemigo interno, asociado a los altos niveles de conflictividad social y política que afrontó el gobierno frondicista (Pontoriero, 2015). 
dido por los núcleos dirigentes". ${ }^{8}$ En efecto, el eje del planteo consistía en cuestionar la "totalitaria" estructura laboral argentina, donde un puñado de dirigentes decidía contra el sentir del conjunto de los trabajadores, por razones políticas y extragremiales. ${ }^{9}$ Demandaban además que el gobierno no permaneciera "neutral", garantizando el funcionamiento de los servicios básicos y modificando la legislación en cuanto al derecho de huelga. "Si el poder ejecutivo limita su acción a solo cuidar que una huelga de esta clase se desarrolle con tranquilidad, no habría cumplido sus funciones", afirmaban. ${ }^{10}$

Incluso las quejas empresarias llegaron a la OIT. En efecto, en la $45^{\text {a }}$ Conferencia de Ginebra de 1961, demandaron sindicatos que "no sean instrumentos de movimientos políticos, generalmente contrarios al fondo de los ideales de libertad de la clase trabajadora" y dejaron sentado que "la huelga solo es admisible como último recurso [...] pero es inaceptable en los diferendos jurídicos". Más claramente, repudiaron "enérgicamente las huelgas politicas y las formas arteras de la acción gremial directa, como es el llamado "trabajo a reglamento" o la disminución deliberada del ritmo de trabajo". ${ }^{11}$ De hecho, el caso argentino era citado por su Director General como un ejemplo destacado de los países en vías de desarrollo que más días perdidos por huelga ostentaba en términos comparativos, configurando más de la mitad del total de jornadas perdidas por un conjunto de once países que contabilizaba el organismo en esa categoría. ${ }^{12}$

Los empresarios de todo el país prestaron especial atención al desarrollo de la prolongada y combativa huelga ferroviaria por tiempo indeterminado y al paro de 72 horas convocado por la Confederación General del Trabajo (CGT) ante el proceso de racionalización y reestructuración ferroviaria. El conflicto fue respondido por el Estado con la

8. "Cuando la decisión de cien paraliza millones de obreros", Boletín, $\mathrm{n}^{\circ}$ 712, 22 de julio de 1961.

9. "El régimen laboral" y "La huelga general del 6 de octubre", Boletín, no 723, 7 de octubre de 1961.

10. "La huelga general del 6 de octubre", Boletín, $\mathrm{n}^{\circ}$ 723, 7 de octubre de 1961.

11. Intervención de Piñol, consejero técnico de los empleadores de Argentina, en OIT, Actas de la Cuadragésima quinta reunión de la Conferencia Internacional del Trabajo, Ginebra, 1961, p. 294, disponible en http://www.ilo.org/public/libdoc/ ilo/P/09656/09656(1961-45).pdf.

12. OIT, Memoria del director general, Informe I, Parte I. Relaciones laborales. Problemas actuales y perspectivas para el porvenir, Ginebra, 1961, pp. 106 y 107, disponible en http://www.ilo.org/public/libdoc/ilo/P/09375/09375(1961-45-part-1).pdf. 
contratación de rompehuelgas, las intimaciones -requisa- para volver al trabajo, allanamientos, cárcel y represión a los activistas. ${ }^{13}$

ACIEL y la rosarina Federación Gremial se refirieron al "proceso de maduración a que nos ha venido sometiendo la izquierda totalitaria". Según su óptica las huelgas no representaban el "normal ejercicio de un derecho constitucional" y pedian la reglamentación del derecho de huelga, con un argumento que aludia a "la condición de rebaño a que se ha sometido al trabajador" motivado por "la regimentación compulsiva que no puede eludir". En consonancia con los discursos circulantes, adjudicaron a la huelga "propósitos francamente subversivos y destructores de la organización social que nos rige". ${ }^{14}$

Para los empresarios ambos conflictos fueron inducidos por los "activistas del partido y las células comunistas", quienes habian "forzado situaciones para sus planes de agitación”. Desde esta particular lectura, consideraron que la convocatoria a la huelga general para el día 7 de noviembre respondió a lo que denominaban el "control remoto de las agitaciones", pues ese día, afirmaban, se conmemoraba el "aniversario de la revolución bolchevique". El objetivo era, en definitiva, producir "el caos". ${ }^{15}$

Estas expresiones dan cuenta del creciente anticomunismo circulante en los discursos empresarios, que acompañaban los fundamentos de la legislación y las prácticas estatales destinadas a los trabajadores y sus conflictos. Se produjo así durante el conjunto del período una deslegitimación de los conflictos obreros, a partir de una operación que consistió en responsabilizar a las direcciones sindicales primero peronistas y luego comunistas ( $\sin$ abandonar la crítica a las primeras, consideradas una herencia duradera del régimen de 1943-1955) de liderar demandas externas a las verdaderas necesidades y motivaciones, reduciendo de ese modo a los trabajadores a simple "rebaño". De conjunto, estas quejas exhibían el descontento ante los escasos logros que consideraban habían logrado los gobiernos desde la caída del peronismo.

\section{El proceso de ocupaciones fabriles bajo el prisma de las organizaciones empresarias}

Si un importante sesgo anticomunista representó la lente a través de

13. Movimiento de Unidad y Coordinación Sindical (MUCS), La heroica huelga ferroviaria, Buenos Aires, julio de 1962 y Schneider, 2005.

14. "Posición de la Federación frente a la huelga" Boletín, no 728, 11 de noviembre de 1961.

15. "La huelga", Boletín, $\mathrm{n}^{\circ} 729,18$ de noviembre de 1961. Para un análisis de la huelga en Buenos Aires, ver Schneider, 2005. 
la cual se leyeron los conflictos laborales del período y sus direcciones, las formas que revistió la lucha obrera pasaron a constituir una fuente medular de preocupaciones empresarias tras el triunfo del radical Arturo Illia en las elecciones de 1963.

A principios de ese año, la CGT había culminado su proceso de normalización y lanzó un Plan de Lucha para el logro de un conjunto de demandas inmediatas tales como: aumentos de salarios, control de costos y fijación de precios máximos para artículos de primera necesidad, plena ocupación, pago de pensiones y jubilaciones atrasadas, créditos para reactivación de la producción, viviendas populares, reincorporación de cesantes por conflictos laborales, entre otras. ${ }^{16}$

Ante su incumplimiento, el Plan de Lucha adoptó a mediados del año siguiente una modalidad diferente: la ocupación masiva y simultánea de centros de producción y establecimientos industriales y de comercialización durante determinados días de los meses de mayo y junio de 1964 en distintas ciudades del país. En paralelo, se produjeron ocupaciones con tomas de rehenes en el marco de conflictos por empresa o rama, que se desarrollaban por fuera del Plan de Lucha, respondiendo a dinámicas propias (Schneider, 2009, y Simonassi, en prensa).

Como era de esperar, las patronales se destacaron por un rechazo homogéneo al Plan, antes, durante y después de su puesta en práctica. Así, la Cámara de Comercio de Buenos Aires lo caracterizó como "un programa revolucionario de ribetes claramente subversivo, que viola elementales disposiciones que hacen a los principios de autoridad, disciplina y convivencia" y denunciaba "implicancias comunistas" ${ }^{17} \mathrm{La}$ organización también responsabilizó al gobierno por el "triste espectáculo del país convertido en escenario del delito de usurpación y de privación de la libertad personal, agravado por la impunidad con que sus instigadores han podido concretarlo luego de cuatro meses de prédica desembozada y disolvente." Para la Cámara, la responsabilidad de los poderes públicos residió en no haber adoptado medidas preventivas y de represión, al tiempo que exigía al presidente de la nación que ejerciese "todo el poder". ${ }^{18}$

La Unión Industrial Argentina (UIA), por su parte, sostuvo que las medidas de lucha no estaban amparadas por el derecho de huelga, sino que representaban "claros delitos contra la propiedad y la seguridad de

16. Confederación General del Trabajo de la República Argentina, Congreso Ordinario realizado en la ciudad de Buenos Aires los dias 28, 29, 30, 31 de enero y $1^{\circ}$ de febrero de 1963 y Segunda etapa del Plan de Lucha de la CGT.

17. La Tribuna, 25 de enero de 1964.

18. La Prensa, 29 de mayo de 1964. 
la Nación". ${ }^{19}$ Para la principal organización de empresarios industriales, la responsabilidad recaía también en "la pasividad del gobierno ante el caos que nos amenaza". ${ }^{20}$

ACIEL acusó al gobierno nacional por la falta de reacción y a la propia CGT -definida como un "factor de poder"-, por llevar a cabo una "gestión extragremial, política en sentido disgregador, negativo, a veces subversivo". ${ }^{21}$ Expresó además su aliento y solidaridad con las firmas afectadas por el plan de lucha, en especial los funcionarios de empresas "víctimas de los excesos de los dirigentes obreros". ${ }^{22}$

Diversos órganos de expresión de ramas industriales se pronunciaron en similar sentido. Fue el caso de Mundo Metalúrgico, que culpó a la CGT por impulsar "un Plan de Lucha revolucionario [que] puede desencadenar gravísimos hechos de impredecibles consecuencias". Los acusaban de: "tomar las fábricas, incomunicándolas con el exterior, y con los patrones como rehenes, alojándolos en habitaciones individuales". Y continuaban señalando con gran elocuencia que de no tomar el gobierno "enérgicas medidas para detener este estado de subversiva violencia, de proteger la vida y bienes de aquellos contra quienes se instrumenta la acción sediciosa, éstos, en uso de un elemental principio de autodefensa, se verán obligados a protegerse por sí mismos", es decir, se desataría una "guerra" que era preciso evitar para salvaguardar la Nación. ${ }^{23}$

El periódico Economic Survey se ocupó detenidamente de analizar el significado de las tomas al caracterizarlas como "el adiestramiento para la subversión", consistentes en acciones orientadas a "transtornar realmente el principio de autoridad en las fábricas" más aún, a destruirlo. El semanario se ocupaba de ilustrar con ejemplos de situaciones acaecidas en distintas fábricas el logro de esos objetivos. La toma de rehenes era calificada como una práctica empleada "por extremistas para llevar adelante sus propósitos". El blanco privilegiado de ataque era el gobierno, por su debilidad, por su falta de acción, aunque resaltaba con preocupación la falta de resistencia de las patronales: "Que un delegado pueda ordenar que se cierren las puertas de la fábrica y que esto se haga sin resistencia real de la gerencia, es una de las lamentables novedades de nuestra época y denota falta de coraje para defender lo que es exclusivo derecho de los patronos". Finalmente, presentaba un conjunto de políticas que el gobierno debía seguir y ofrecía una especie

19. Solicitada de la UIA, La Razón, 1 de febrero de 1964, citado en Schneider, 2009.

20. La Prensa, 30 de mayo de 1964.

21. "Editorial: Lo que necesita la república", Revista Federación Gremial del Comercio y la Industria de Rosario (de aquí en adelante, Revista), n 214, enero-febrero de 1964.

22. "De ACIEL", Revista, no 414, mayo-junio de 1964.

23. "Editorial”, Mundo Metalúrgico, n 205, abril de 1964, citado en Schneider, 2009. 
de instructivo a los patrones para actuar ante nuevas tomas, en todos los casos de carácter antiobrero, antisindical y represivo. ${ }^{24}$

En Rosario el panorama no era demasiado diferente. Federación Gremial reprodujo las posturas de la liberal ACIEL. La Bolsa de Comercio expresó también su rechazo al Plan de Lucha y advirtió sobre los delitos que cometerian las comisiones de activistas que, afirmaban, controlarian los mercados, las ferias y los comercios. La entidad rosarina planteó que se trataba de "una sistemática acción contra el orden" de modo que "la sola difusión del plan encierra una amenaza cuya efectivización debe ser impedida anticipadamente". Denunciaron su carácter "sedicioso" y postularon "la necesidad de su represión". ${ }^{25}$ Poco después exigieron a Illia que "adopte resoluciones" para restablecer "las formas pacíficas del entendimiento" violado por el "prolongado y agraviante plan de lucha". ${ }^{26}$

Los metalúrgicos locales, por su parte, se negaron a concurrir a discutir el nuevo convenio en el mes de junio, amparados en las ocupaciones de fábrica. Afirmaron que hasta que no se normalizara "el estado de subversión" no se sentarían a negociar. En el orden provincial protestaron por la inactividad policial ante las "violaciones a los derechos de libertad y propiedad". ${ }^{27}$

En términos similares, la prensa rosarina cuestionaba el Plan de Lucha. La Tribuna advertía que existía un notable encarecimiento de la vida, lo cual otorgaría sólidas razones a las protestas. Sin embargo, las ocupaciones no eran aprobadas ni convenientes porque "alcanza instrumentos de agitación a los extremistas infiltrados en el movimiento obrero." Y agregaba "hay "guerrilleros" sin armas en toda la República". ${ }^{28}$

Así, las organizaciones patronales percibieron el método de las ocupaciones como un peligro, como violatorio del derecho de propiedad y las libertades individuales, agravado por la falta de intervención estatal en la prevención o finalmente, la represión. Este método de lucha configuraba en sí mismo un cuestionamiento al poder patronal en las plantas, que remitía al papel cumplido por los delegados y las comisiones internas en la tradición obrera y sindical argentina. Pero era leído bajo nuevas

24. Economic Survey, "El adiestramiento para la subversión y la ceguera del gobierno", 26 de mayo de 1964.

25. La Tribuna, 8 de febrero de 1964, y Bolsa de Comercio de Rosario, Memoria y Balance, años 1964 y 1965.

26. La Prensa, 5 de junio de 1964.

27. Cámara de Industriales Metalúrgicos de Rosario, Actas de Consejo Directivo (CIM-CD), tomo 6, $\mathrm{n}^{\circ}$ 481, 1 de junio de 1964, folios 136-143 y ss.; "Reclámase ante el ejecutivo provincial por su conducta para con los empresarios”, Revista, $\mathrm{n}^{\circ} 414$, mayo-junio de 1964.

28. La Tribuna, 18 de mayo de 1964. 
perspectivas y discursos que asumían el peligro de la extensión de la lucha armada a nivel continental, potenciada tras la Revolución Cubana, temor que parecía confirmarse mediante la actuación en el norte argentino de la guerrilla del Ejército Guerrillero del Pueblo (EGP) y, poco después de culminadas las ocupaciones, por la explosión ocurrida en un departamento del centro de Buenos Aires que reveló los preparativos para un combate armado. Por eso los empresarios cuestionaron duramente la pasividad -debilidad-del gobierno en la represión, el desalojo y el encarcelamiento ante las ocupaciones. Si bien la prensa registra hechos de este tipo, así como la judicialización del tema, las acciones previstas se realizaron, la represión no fue suficiente para frenarlas y el sindicalismo salió fortalecido, siempre de acuerdo a la óptica empresaria.

\section{Radicalización y lucha armada: "subversivos" y "gente de buena voluntad"}

Un golpe de Estado terminó con el gobierno del radical Illia en junio de 1966 y designó como presidente de facto al general Juan Carlos Onganía. A diferencia de otras dictaduras militares previas, el nuevo gobierno respondía a los principales parámetros de la Doctrina de la Seguridad Nacional que se afirmaba en América Latina, orientada a la defensa de las "fronteras ideológicas". Luego del golpe militar, se "profundizó la tendencia a concebir al país como un campo de batalla de la Guerra Fría" y adquirió particular relevancia la protección frente al "enemigo interno". Para cumplir este objetivo se sancionó un nuevo instrumento legal, la Ley de Defensa Nacional, que contemplaba los problemas de "seguridad nacional" en tiempos de paz. La ley planteaba una idea sobre la defensa nacional que permitía neutralizar "las perturbaciones internas producidas por actos humanos", habilitando la actuación de las Fuerzas Armadas en caso de "conmoción interior". Mediante esta ley se creaba el Consejo Nacional de Seguridad (CONASE). En rigor, el gobierno de Onganía y su Ley de Defensa venían a concretar ideas ya circulantes durante los gobiernos democráticos precedentes, que otorgaban un carácter bélico a las expresiones de protesta y conflictividad de distintos sectores (Pontoriero, 2018).

En lo sindical representó un momento de fortalecimiento de la tendencia negociadora del sindicalismo, frente a la cual se conformó en 1968 una nueva central, la CGT de los Argentinos, fundada sobre premisas antiburocráticas y combativas. A esta última adhirieron las principales regionales del interior, entre las cuales se contaba Rosario. La política económica del gobierno condujo a la lucha a diversos sindicatos, tales como azucareros, ferroviarios y portuarios. Diversas politicas implementadas hacia el movimiento obrero y sindical fueron 
acumulando un descontento que se expresó en las jornadas de mayo de 1969 en Córdoba y mayo y septiembre en Rosario.

El Cordobazo se destacó por la magnitud y las modalidades de lucha adquiridas por la conflictividad social, que articuló protesta obrera, insurrección popular y rebelión urbana (Brennan y Gordillo, 2008). El Rosariazo de setiembre de 1969 representó otra coyuntura relevante desde el punto de vista de la conflictividad laboral y social del interior desde donde poder analizar los discursos empresarios. En efecto, tras un paro lanzado por los ferroviarios, se vivieron en la ciudad de Rosario dos jornadas de lucha con focos insurrectos y columnas de obreros en diferentes sitios de la ciudad, a las cuales se sumaron sectores medios y estudiantiles subordinados al movimiento sindical (Peréz y Viano, 1994).

Ante estos acontecimientos, diversas organizaciones empresarias -entre las que se contaban la Asociación de Industriales Metalúrgicos de Rosario (AIM), la Federación Gremial, la Sociedad Rural y la Bolsa de Comercio local-, elevaron una nota al Ministro del Interior ante lo que consideraron "tremendos sucesos que conmovieron a nuestra ciudad y alarmaron a todo el país". Manifestaron que un sector de la sociedad habia actuado "inexplicablemente desbordado y actuando como en plena guerra: nadie cree que se hubiese tratado de una mera "gimnasia" revolucionaria, sin otro trasfondo; por el contrario, no puede sino pensarse que se trata de una acción francamente rebelde, destinada a provocar el caos a través del relajamiento de la vigencia de nuestras instituciones". Denunciaron también el carácter de la actuación de las fuerzas represivas -en particular la ineficacia de la policía provincial y la demora en intervenir de las Fuerzas Armadas-y el ataque "por manos armadas de teas incendiarias". Se solicitaba la investigación de la "infiltración de agentes del desorden en organismos obreros, los cuales no pueden ser inmunes, como no lo son otros sectores de la comunidad, pese al mucho celo que pongan los dirigentes para evitarlo". Consideraban que esos "arrebatos y desmanes" desvirtuaban el derecho a huelga y al trabajo. ${ }^{29}$ La Asociación Empresaria de Rosario, por su parte, responsabilizó a la CGT por los "actos de terrorismo" y pidió a la justicia "actuar con toda la fuerza de la ley" (Pérez y Viano, 1994).

El gobernador de la provincia declaró que el "movimiento ha sido de corte subversivo, preparado y organizado por elementos adiestrados en la guerrilla urbana, que acopló a gente de buena voluntad". De modo similar se pronunció el Ministro del Interior, al afirmar que en Rosario actuaron "elementos extragremiales", donde problemas económico-sociales "no 
graves" provocaron conflictos que fueron "aprovechados por sectores politizados y subversivos" tendientes "al caos y a la destrucción". ${ }^{30}$

Con gran elocuencia y una mirada más general, Economic Survey denunciaba un "vasto plan de conmoción organizada", materializado en la "inusitada virulencia" de la huelga ferroviaria del ferrocarril Mitre, los atentados contra trenes, la ocupación de la empresa Fiat en Córdoba, la toma de rehenes y el paro de 36 horas convocado por la CGT en Rosario y Córdoba, todo lo cual configuraba "un panorama de verdadera subversión" tendiente a derribar al gobierno. ${ }^{31}$ Un ejemplo venía a ilustrar para el caso de Rosario este carácter organizado y peligroso: la existencia de al menos dos activistas heridos que no entraron a los hospitales: "Ese particular interés en mantener oculta la identidad de los heridos es característica de una organización de verdadera guerrilla metropolitana". ${ }^{32}$

Consideraban que el gobierno era responsable, por no ejercer una función educativa - "didáctica"- sobre los trabajadores explicando "la estrategia del plan económico, las ventajas de la estabilidad y la necesidad de proteger el salario real"; dicho plan, muy por el contrario, aparecía como "antisocial y carente de sensibilidad popular". Para Economic Survey, determinados sectores laborales creían de buena fe que esto era así, porque "nadie les ha explicado lo contrario", distinguiéndose así de aquellos que "se interesan en el caos como medio para disolver la sociedad".

Era la propia tendencia negociadora e inconsecuente de las dirigencias sindicales la que-siempre según este medio-empujaba a las bases a dar la espalda a sus propios dirigentes y abrazar una "linea dura". "E1 mejor negocio -afirmaban- es el de la subversión". Para la publicación empresaria, la solución era lisa y llanamente asumir una actitud sin concesiones para que "desaparezca" la subversión. ${ }^{33}$

La publicación no dejaba de resaltar el hecho de que un gobierno militar, "en ejercicio del estado de sitio", no pudiese impedir insurrecciones que no se producian siquiera en gobiernos civiles. Como los empresarios rosarinos, la publicación denunciaba la demora en convocar a los militares "imprescindibles para restablecer y salvaguardar el más elemental orden urbano", ante la impotencia, la inacción de la policía, que -en Santa Fe como en todo el país- "se descontaba por anticipa-

30.El Litoral, 19, 20 y 24 de septiembre de 1969.

31.Economic Survey, Buenos Aires, 16 de septiembre de 1969.

32."La pérdida de autoridad", Economic Survey, 23 de septiembre de 1969.

33.Economic Survey, Buenos Aires, 16 de septiembre de 1969. Destacados en cursiva en el original. 
do". Y concluían: "No hay gobierno"; "este no es más el gobierno de la revolución argentina". ${ }^{34}$

En rigor, el Cordobazo, el Rosariazo y los procesos de lucha que sacudieron otras ciudades argentinas en 1969 desgastaron a la dictadura y abrieron una etapa de radicalización política y social. La Córdoba automotriz y el cordón industrial del sur de la provincia de Santa Fe fueron algunos de los epicentros de la radicalidad obrera durante la primera mitad de la década del 70. En Rosario en 1970 comenzaron a actuar las organizaciones armadas y se avanzó en la aplicación de la legislación represiva.

En ese contexto, otro momento clave en la intervención pública del empresariado rosarino estuvo constituido por el asesinato, por parte de un comando conjunto del ERP y las FAR, del comandante del II Cuerpo de Ejército, general Juan Carlos Sánchez, el 10 de abril de 1972 en el centro de la ciudad.

Los empresarios rosarinos lo adjudicaron a "agentes provocadores de los disturbios callejeros", pues "no son otros los que, con diversos nombres y siglas, asaltan y asesinan respondiendo a consignas ajenas a nuestras ideas y convivencia". Nuevamente afirmaban que el objetivo primordial de estos grupos consistía en la destrucción de las "instituciones que caracterizan nuestro estilo de vida en libertad, para entronizar aquí filosofias extremas y extrañas que no condicen con la idiosincrasia del hombre argentino". Para ellos la violencia arrastraba "a hombres y mujeres jóvenes que salen de las casas de estudio a las que ingresaron como esperanza del futuro argentino". Así, señalaban a sectores del estudiantado, mientras los trabajadores, quienes soportaban "las contingencias adversas de la economía con mayor rigor", se marginaban de esos hechos "por propia y noble determinación". ${ }^{35}$

Varias organizaciones empresarias de la ciudad unieron sus voces para condenar y repudiar los asesinatos, que constituian hechos que "definen y compendian [...] la filosofia y el programa de quienes desde hace ya largo tiempo están empeñados en sembrar el caos y la confusión en nuestra patria" y consideraron que había "llegado la hora de tomar posiciones claras y definidas: se está por la ley y el orden o por la violencia y la destrucción de nuestro estilo de vida". ${ }^{36}$

De modo que en 1969 ya resultaba visible que para los empresarios los problemas habian cambiado su carácter: expresiones como "vasto

34."La pérdida de autoridad", Economic Survey, 23 de septiembre de 1969.

35. "Responsabilidad total frente a la violencia", Dinámica, Órgano de la Federación Gremial del Comercio y la Industria de Rosario, año IV, n 16, enero-marzo de 1972. 36."Sacudió dolorosamente a nuestra ciudad el asesinato del General Juan C. Sánchez”, Dinámica, año IV, n 16, enero-marzo de 1972. 
plan de conmoción organizada", "infiltración de agentes del desorden", "actos de terrorismo", "movimiento de corte subversivo, preparado y organizado por elementos adiestrados en la guerrilla urbana", dan cuenta de la aparición de un enemigo de otro carácter. Aparece además la apelación a las Fuerzas Armadas para intervenir en la imposición del orden al interior de las fronteras nacionales, legitima y necesaria a sus ojos, ya sea por la inacción policial o por la intensidad y las modalidades revestidas por la movilización social y politica.

En ocasión del denominado segundo Rosariazo, un proceso de fuerte movilización obrera, con acontecimientos desarrollados en medio de un paro activo, se responsabilizaba a infiltrados externos a la clase. El enemigo, según estos discursos, "se enquista" en organizaciones de diverso tipo, como las sindicales, y a pesar de los esfuerzos en contrario por parte de sus dirigentes. Además, esa condición de exterioridad de los "infiltrados", "agentes del desorden" "sectores politizados y subversivos" parecía dejar por fuera a los trabajadores de base, a quienes aún se les adjudicaba "buena fe". En el asesinato de Sánchez aparecieron los estudiantes - "hombres y mujeres jóvenes"- como vehículos del accionar de las organizaciones armadas, dejando explícitamente por fuera a los trabajadores. No obstante, advertian que frente a las actitudes sindicales (podriamos agregar empresarias y gubernamentales), los trabajadores podian abrazar "la línea dura", que en otros términos significaba adherir a las corrientes clasistas y combativas del sindicalismo argentino o a las organizaciones armadas. Quedaba de ese modo abierta la posibilidad de generalización de esos rasgos al conjunto de la clase trabajadora. ${ }^{37}$

\section{Disciplinamiento laboral y prácticas paternalistas}

Una vasta producción académica ha enfatizado la tendencia de las burguesías, en diferentes latitudes, coyunturas históricas y ramas de actividad, por promover la armonía y la paz laboral a través de diversos mecanismos. Así, una amplia producción ha mostrado que estos esfuerzos configuraron aspectos medulares de las relaciones capital trabajo (Badaloni y Simonassi, 2013). Se ha reconocido que uno de los motivos que impulsó su despliegue consistió en atenuar la lucha de clases y dirigir los esfuerzos hacia la constitución de un "obrero modelo", aislando a los activistas y promotores de conflictos, para disciplinar, en suma, a la fuerza de trabajo. Sin embargo, las articulaciones entre

37. El desplazamiento en la identificación del enemigo, desde las "minorías externas", hacia la idea de "subversión industrial" que justificó el despliegue de la represión hacia el conjunto de la clase trabajadora, ha sido analizado en Carminati, 2018. 
esos esfuerzos y su efectividad para frenar huelgas y conflictos obreros ha sido menos estudiada. ${ }^{38}$

Los empresarios argentinos durante la convulsionada década del 60 no permanecieron al margen de esos esfuerzos. Al tiempo que, como analizamos hasta ahora, amplios sectores demandaron modificaciones en la legislación, impulsaron la represión estatal y modificaron sus discursos al compás de los clivajes de los debates públicos, promovieron en sus plantas múltiples y heterogéneos dispositivos de control y disciplinamiento en sus plantas. En el caso de la industria de capitales nacionales, esto fue posible en buena medida debido al proceso de expansión protagonizado por aquellas plantas que lograron aprovechar las oportunidades de asociación con los capitales extranjeros que ingresaron durante estos años gracias al otorgamiento de generosas concesiones. De modo que durante estos años el recurso a las prácticas paternalistas creció en proporción a las nuevas posibilidades abiertas por las transformaciones estructurales en curso.

Las diversas fuentes consultadas refieren a diversos recursos utilizados por empresas de diversos tamaños, ramas de producción y origen de los capitales. Esos dispositivos incluyeron desde el estrechamiento de relaciones directas entre trabajadores y patrones hasta mecanismos más complejos. Así, la construcción de viviendas, la inauguración de escuelas-fábrica, la conformación de cooperativas de provisión y ayuda mutua, la implementación de comedores y clubes deportivos y la organización de celebraciones donde se distribuian obsequios para las familias de los trabajadores constituyeron algunos de los dispositivos que destinaron a los fines de mitigar o neutralizar los efectos de la lucha obrera. El aprendizaje de trabajadores menores fue una de las prácticas desplegadas desde el peronismo a los fines de formar mano de obra calificada y habituada a criterios paternalistas. La construcción discursiva de la "gran familia" sintetizaba estos esfuerzos (Simonassi, 2007).

Así, si en las grandes fábricas estas prácticas son más conocidas, en las medianas empresas de capitales nacionales de Rosario también fueron frecuentes. El propietario de una autopartista de la zona sur del Gran Rosario relataba, por ejemplo, que sobre fines de la década promovieron la creación de la "Caja Mutual de Ayuda Social" en su fábrica,

38. Hemos analizado las maneras en que se edificaron en la industria metalúrgica de Rosario -de pequeñas y medianas dimensiones y de capitales nacionales-, desde la década de 1940, relaciones de tipo paternalista, para diferenciarlas del paternalismo como régimen industrial. En ese mismo lugar estudiamos el inicio de una etapa de agotamiento de dichas prácticas, como resultado directo de la conflictividad social y laboral del periodo 1973-1976 (Simonassi, 2007). Similares dispositivos configuraron el "régimen industrial con rasgos de paternalismo" analizado por Paula Varela para FATE (Varela, 2015). 
adquiriendo la casa para hacerla funcionar y nucleando empleados y obreros. Allí implementaron cursos de repostería, cocina, bordado, corte y confección, mecanografia, contabilidad, electricidad y otros oficios, además de un jardín de infantes y una escuela de alfabetización de adultos. Se enseñaba "economia, economía hablando de la economía de la casa, economía doméstica, donde se enseñaba con un kilo de harina qué es lo que se podía hacer, cuánto era el costo diario de una casa de cuatro personas, con el salario de un obrero qué se podía hacer, qué se podía comprar, en ropa; enseñaban a planchar, a la gente que no sabía enseñaron a arreglar ropa, remiendos, bordado". ${ }^{39}$ Los dueños de la fábrica Galizia y Bargut se jactaban durante un duro conflicto con sus trabajadores, de contar con "asistencia social modelo, con prestaciones médicas, operaciones, farmacia, bioquímica, cirugia, odontología, préstamos personales sin interés, seguro de vida, subsidio por fallecimiento y equipo de fútbol con los gastos a cargo de la empresa". ${ }^{40}$

Durante la década se abrieron también numerosas escuelas-fábrica, como la habilitada en la rosarina GEMA de maquinarias agrícolas en abril de 1960, para la formación de aprendices y la capacitación en cursos nocturnos del conjunto del personal. Posteriormente incorporaron cursos de inglés e implementaron, durante los recreos y clases de dibujo, la difusión de música clásica y folklore nacional. ${ }^{41}$ En la cercana MIGRA, de la misma rama de producción, también funcionó sobre fines de la década una escuela de oficio para torneros. ${ }^{42}$

Relativamente alejada de las grandes ciudades, en comunidades urbanas más pequeñas, grandes fábricas metalúrgicas como Vassalli construyeron un jardín de infantes para hijos del personal, una escuela de artesanía para jóvenes de entre 12 y 18 años donde se impartian clases de dibujo, pintura, escultura, torneado de madera, hierro forjado, plomeria, electricidad de la vivienda, decoración, grabado en cobre, entre otras actividades, y otorgaron becas para hijos que realizaban estudios secundarios y universitarios. También construyeron un departamento de odontología y medicina infantil, implementaron descuentos en farmacias y vacunaciones masivas. Promovieron actividades sociales y deportivas mediante el acceso gratuito al club presidido por Roque

39. Entrevista realizada al empresario A.S. el 4 de mayo de 1996, intervención de su esposa, quién participó activamente en la Mutual.

40. La Capital, 26 de septiembre de 1974. Para este conflicto consultar Simonassi (2007) y Carminati (en prensa).

41. GEMA, Memoria y Balance General,1960, 1961 y 1963, y La Capital, 19 de abril de 1960.

42. Entrevistas realizadas a Rubén y Manuel, obreros metalúrgicos, Rosario, noviembre de 1997 y junio de 1996. 
Vassalli, garantizando vacaciones para los niños, todo lo cual se orientaba a la construcción de una "comunidad armónicamente integrada". ${ }^{43}$

De modo que estas prácticas sustentaron la idea de la "gran familia" y confluyeron con los discursos que diferenciaban el activismo que promovia artificialmente los conflictos, de los "verdaderos" trabajadores. Como ha afirmado Carminati (2018), "desde cierta actitud paternalista, se construía la imagen de una masa obrera "inocente" que era influida por "agitadores foráneos"”.

\section{Consideraciones finales}

En este artículo analizamos las formas que adoptaron los discursos y las prácticas patronales durante los años 60 y los primeros años de la década siguiente, que en lo sustancial acompañaron los discursos circulantes entre las Fuerzas Armadas, los partidos políticos y la prensa del periodo.

En primer lugar, analizamos las transformaciones producidas en la mirada sobre los conflictos y las direcciones sindicales a principios de la década. Mostramos la persistente preocupación por el crecimiento de la conflictividad laboral y la desazón de buena parte del empresariado ante la imposibilidad, del gobierno militar primero y el frondicismo después, de disciplinar la mano de obra. Tras la caída del peronismo y al menos hasta 1962, deslegitimaron los conflictos obreros responsabilizando a las direcciones sindicales peronistas primero y comunistas después. En dicho desplazamiento influyó el anticomunismo potenciado tras la revolución cubana en buena parte de Latinoamérica. Además las demandas eran consideradas artificiales, impuestas por motivos politicos por direcciones sindicales que permanecian alejadas de los verdaderos trabajadores y sus genuinas necesidades.

Para 1964, las modalidades de la lucha obrera adquirieron centralidad en las preocupaciones empresarias, en especial las ocupaciones fabriles, el método adoptado a mediados de ese año por la CGT como parte de su Plan de Lucha. Si bien tomaron estado público en esa oportunidad, venían formando parte del repertorio de lucha de los trabajadores y en algunos casos fue acompañada de toma de rehenes. Las patronales las rechazaron, subrayando el carácter violatorio del derecho de propiedad y de las libertades individuales, lo asociaron a un plan subversivo, clamaron por la utilización de la represión y cuestionaron duramente la debilidad del gobierno. Si bien incipiente, los episodios de lucha armada que se habian iniciado en Argentina, que internalizaban dentro de las fronteras nacionales el "peligro" cubano, proveyeron

43. Roque Vassalli S.A., Memoria y Balance, 1974, y Simonassi, 2011. 
la lente a partir de la cual caracterizar la coyuntura de lucha obrera e insertarla en un contexto más amplio.

Ya durante el onganiato, el Rosariazo de septiembre de 1969, iniciado con una huelga ferroviaria, fue interpretado como una "acción francamente rebelde", como "actos de terrorismo", "un panorama de verdadera subversión", "un vasto plan de conmoción organizada", con un activismo que adoptaba métodos de guerrilla para derribar el gobierno. En este caso, las organizaciones obreras habian sido infiltradas, a pesar del "mucho celo" de los dirigentes sindicales por evitarlo. Sin embargo, debieron explicar la adhesión y participación de amplios sectores obreros y lo hicieron aludiendo al engaño y la falta de información.

El asesinato del comandante del II Cuerpo del Ejército en Rosario en 1972 vino a confirmar sus diagnósticos. Nuevamente los trabajadores, identificados con la "idiosincrasia argentina", que no abrazaban ideas foráneas, no fueron responsabilizados. Sin embargo, advirtieron sobre el peligro que revestía la deslegitimación de ciertas fracciones de la dirigencia sindical tradicional y las posibilidades de radicalización que ello podia habilitar. En correspondencia con las ideas circulantes, eran las Fuerzas Armadas las que debian actuar ante situaciones como las analizadas.

Finalmente, hemos relevado otras formas de disciplinamiento de la fuerza de trabajo, en particular la implementación de prácticas y dispositivos paternalistas en las plantas industriales. En estos casos, la condición de "rebaño" que reservaban las patronales a las masas trabajadoras confluyó con los esfuerzos orientados a evitar los conflictos y aislar el activismo y la acción sindical. Las formas que adquirió el conflicto de clase tras el retorno del peronismo al poder mostró el progresivo agotamiento de las prácticas paternalistas y abrió un proceso de represión hacia amplios sectores de la clase trabajadora, bajo los supuestos de la generalización de la subversión industrial y la guerrilla fabril.

\section{Bibliografía}

Acha, Omar (2008), Las huelgas bancarias, de Perón a Frondizi (1945-1962), Buenos Aires: Ediciones del CCC.

Badaloni, Laura y Silvia Simonassi (2008), "Asociacionismo empresario y conflictividad social en la Rosario de entreguerras”, en Sandra Fernández y Oscar Videla (comps.), Ciudad oblicua. Aproximaciones a temas e intérpretes de la entreguerra rosarina, Rosario: La Quinta Pata-Camino Ediciones.

- (2013), "Trabajadores, empresas y comunidades urbanas: reflexiones introductorias", en Avances del CESOR, año 10, n 10, pp.101-111. 
Brennan, James y Mónica Gordillo (2008), Córdoba rebelde. El Cordobazo, el clasismo y la movilización social, La Plata: De la campana.

Carminati, Andres (2018), "Del "ausentismo" a la "subversión industrial". La construcción discursiva de un enemigo (1974-1976)", en Silvia Simonassi y Daniel Dicósimo (coords.), Trabajadores y sindicatos en Latinoamérica. Conceptos, problemas y escalas de análisis, Buenos Aires: Imago Mundi.

- (en prensa), “Elementos extraños con brazaletes rojos". Radicalización obrera y lucha armada en una metalúrgica mediana de la ciudad de Rosario (1973-1976)", en Alejandra Ciriza (comp.), La centralidad de la politica en los 70. Lecturas sobre un tiempo disruptivo, Mendoza: EDIUNC.

Caruso, Laura (2016), Embarcados. Los trabajadores maritimos y la vida a bordo. Sindicato, empresas y Estado en el puerto de Buenos Aires, 18891921, Buenos Aires: Imago Mundi.

Cúneo, Dardo (1984), Comportamiento y crisis de la clase empresaria, vol. 2, Buenos Aires: CEAL.

Franco, Marina (2012a), Un enemigo para la nación. Orden interno, violencia y “subversión", 1973-1976, Buenos Aires: FCE.

- (2012b), "Rompecabezas para armar: la seguridad interior como política de Estado en la historia argentina reciente (1958-1976)", Contemporánea, año 3, vol. 3, pp.77-95.

James, Daniel (1981), "Racionalización y respuesta de la clase obrera: contexto y limitaciones de la actividad gremial en la Argentina", en Desarrollo Económico, vol. 21, no 83, octubre-diciembre de 1981, pp. 321-349.

Mazzei, Daniel Horacio (1997), "Primera Plana: modernización y golpismo en los sesenta", en Realidad Económica, n 148.

Pérez, José y Cristina Viano (1994), "El 69: del mayo rosarino al Rosariazo", en Patricia Berrotarán y Pablo Pozzi, Estudios inconformistas sobre la clase obrera argentina (1955-1989), Buenos Aires: Letra Buena.

Pontoriero, Esteban (2015), "Estado de excepción y contrainsurgencia: el Plan Conintes y la militarización de la seguridad interna en la Argentina (1958-1962)", Contenciosa, año III, no 4, pp. 1-16.

Pontoriero, Esteban (2018), "La seguridad interna como campo de batalla de la "guerra revolucionaria": contrainsurgencia y defensa nacional en los ámbitos político y militar en Argentina (1963-1970)", Boletín del Instituto de Historia Argentina y Americana "Dr. Emilio Ravignani", $\mathrm{n}^{\circ}$ 48, pp. 84-120.

Ranalletti, Mario (2011), "Una aproximación a los fundamentos del terrorismo de Estado en la Argentina: la recepción de la noción de "guerra revolucionaria" en el ámbito castrense local (1954-1962)", en Anuario del Centro de Estudios Históricos Prof. Carlos S. A. Segreti, Córdoba, $\mathrm{n}^{\circ}$ 11, pp. 261-278.

Salas, Ernesto (2006), La resistencia peronista. La toma del Frigorífico Lisandro de la Torre, Buenos Aires: Retórica-Altamira.

Schneider, Alejandro (2005), Los compañeros. Trabajadores, izquierda y peronismo, 1955-1973, Buenos Aires: Imago Mundi. 
- (2009), Algunas consideraciones sobre las ocupaciones fabriles en la década de 1960, Buenos Aires: Herramienta.

Simonassi, Silvia (2007), "Conflictividad laboral y politicas disciplinarias en la industria metalúrgica de la ciudad de Rosario 1973-1976”, en Anuario IEHS, $\mathrm{n}^{\circ} 22$, pp. 465-486.

- (2011), "Labor and Community in post war Argentina: the Agro-Machinery Industry in Firmat, Santa Fe", Oliver Dinius y Angela Vergara (eds.), Company Towns in the Americas: landscape, power, and Working-Class Communities, Athens: The University of Georgia Press.

- (2014), "Prácticas asociativas e identidades: el empresariado industrial metalúrgico rosarino, la conflictividad laboral y la organización obrera en la etapa formativa del peronismo", en Maria Celia Bravo y Sandra Fernández, Formando el espacio público. Asociacionismo y política. Siglos $X I X$ y XX, San Miguel de Tucumán: EDUNT.

- (en prensa), "El Plan de Lucha de la CGT argentina y las dinámicas regionales de la conflictividad en el Gran Rosario hacia mediados de la década de 1960".

Varela, Paula (2015), La disputa por la dignidad obrera. Sindicalismo de base fabril en la zona norte del Conurbano bonaerense 2003-2014, Buenos Aires: Imago Mundi. 